\title{
The Effect of Logotherapy on Depression in Breast Cancer Patients Under Chemotherapy
}

\author{
Sri Burhani Putri, Miftahul Jannah
}

\begin{abstract}
Background: Chemotherapy is the treatment most often carried out by breast cancer patients with psychological side effects are stress. Logotherapy is one therapy that can be used as a stress management for cancer patients. Methods: The design of this study was quasi-experimental pre-post with control group. The study was conducted at Dr. M Djamil General Hospital, Padang City, West Sumatera Province, Indonesia. Data collection was carried out using the Depression Anxiety and Stress Scale (DASS) instrument and the University of Indonesia Mental Health Nursing Therapy Module. Results: The results showed the characteristics of breast cancer patients undergoing chemotherapy mostly over 45 years, Minangkabau Ethnicity, married status, long since diagnosis of cancer less than 2 years, stage 3 and long time undergoing chemotherapy less than 3 years and experiencing moderate stress levels and statistical test $(\mathbf{p}<0.05)$ Conclusion: There is a significant difference between stress levels of breast cancer patients undergoing chemotherapy before and after logotherapy intervention.
\end{abstract}

Index Terms - chemotherapy, logotherapy, stress

\section{INTRODUCTION}

Breast cancer is the most frequent cancer in women in the world. It is estimated that 1.4 million new cases of breast cancer occur and 450,000 women die each year. The incidence of breast cancer in developing countries continues to increase at least partially due to lifestyle changes [1]. In Indonesia there are thought to be 40 cases per 100,000 women with a total of almost 40,000 new cases each year. The report from the National Hospital Data Base in 2007 showed breast cancer is the most commonly treated cancer in women and the leading cause of cancer death that most treated in women and also the most common cause of death from cancer in women who were treated in hospitals [2].

Breast cancer patients who under chemotherapy will experience physiological and psychological side effects. Psychological side effects experienced by breast cancer patients who under chemotherapy can be the emergence of feelings, such as helplessness, loss of hope, perceiving disease as a punishment, and consider themselves as a burden to others who can refer to suicidal acts [3]. Previous study showed that breast cancer patients who experience stress report more physiological symptoms, such as constipation, diarrhea, fatigue, nausea and vomiting, pain, dyspnea, insomnia, and loss of appetite [4].

Breast cancer patients who under chemotherapy are prone

Sri Burhani Putri Nursing Study Program, Piala Sakti School of Health, Pariaman, West Sumatera Province, Indonesia

Miftahul Jannah, Nursing Study Program, Piala Sakti School of Health, Pariaman, West Sumatera Province, Indonesia to stress. One of the negative effects of stress experienced is inhibiting the success of treatment, therefore handling stress in breast cancer patients needs special attention. The eighth goal of the World Cancer Declaration states that one of the goals of treating cancer patients is to reduce pain and stress management [5].

\section{MATERIALS AND METHODS}

\section{A. Study Design and Research Sample}

The design of this study was quasi-experimental pre-post with control group. The study was conducted at Dr. M Djamil General Hospital, Padang City, West Sumatera Province, Indonesia. Sample size 70 people with two groups consist of breast cancer patients who under chemotherapy and not. Data collection was carried out using the Depression Anxiety and Stress Scale (DASS) instrument and the University of Indonesia Mental Health Nursing Therapy Module. Test the normality of data by Shapiro-Wilk test and hypothesis test using paired $\mathrm{t}$ test. A two-tailed $P$-value of $<0.05$ was considered statistically significant.

\section{B. Operational Definitions}

The variables of this study included independent variable is logotherapy intervention and dependent variable is depression in breast cancer patients under chemotherapy.

\section{Data Collection Technique}

This study was approved by the Ethical Committee of Dr M Djamil General Hospital, Padang City, West Sumatera Province, Indonesia. The instrument used in this study was DASS to measure patient stress consisting of 14 questions and mental nursing therapy module NERS Study Program Psychiatric Nursing Specialist Faculty of Nursing University of Indonesia as a guideline for implementing logotherapy consisting of 4 sessions, including fostering trusting relationships, identifying patient response and response to problems, medical ministry and evaluation technique. Pretest session, at this stage the stressors of breast cancer patients who underwent chemotherapy were measured using the DASS instrument for all 70 respondents. The stages of intervention, at this stage the respondents were divided into 2 groups, namely the intervention group and the control group with a total of 35 people for each group. In the intervention group there were 4 sessions of logotherapy and in the control group no logotherapy was given. One week after the last session was completed, stress measurements were carried out in the intervention group and the control group using the DASS instrument and leaflets were given about stress management. 


\section{Data Analysis}

The quantitative variables were recorded as Mean $\pm \mathrm{SD}$, median and percentage. Test the normality of data by Shapiro-Wilk test and hypothesis test using paired t test. A two-tailed $P$-value of $<0.05$ was considered statistically significant. A two-tailed $P$-value of $<0.05$ was considered statistically significant. Data were analyzed using the Stata version 14.2 (Stata Corporation).

\section{RESULTS}

Characteristics of respondents (Table 1).

Table 1: Characteristics of respondents

\begin{tabular}{lcccccc}
\hline \multirow{2}{*}{ Characteristics } & \multicolumn{2}{c}{$\begin{array}{c}\text { Intervention } \\
\text { Group }\end{array}$} & \multicolumn{2}{c}{$\begin{array}{c}\text { Control } \\
\text { Group }\end{array}$} & \multicolumn{2}{c}{ Total } \\
\cline { 2 - 7 } & f & \% & f & \% & f & \% \\
\hline Age (years) & & & & & & \\
$\leq 45$ & 24 & 68.57 & 25 & 71.4 & 49 & 70.0 \\
$>45$ & 11 & 31.43 & 10 & 28.6 & 21 & 30.0 \\
\hline Ethnicity & & & & & & \\
Minangkabau & 23 & 65.7 & 25 & 71.4 & 48 & 68.6 \\
Not Minangkabau & 12 & 34.3 & 10 & 28.6 & 22 & 31.4 \\
\hline Maritak Status & & & & & & \\
Married & 28 & 80.0 & 29 & 82.9 & 57 & 81.4 \\
Single & 7 & 20.0 & 6 & 17.1 & 13 & 18.6 \\
\hline Long of diagnosed & & & & & & \\
cancer (years) & & & & & & \\
$\leq 2$ & 26 & 74.3 & 23 & 65.7 & 49 & 70.0 \\
>2 & 9 & 25.7 & 12 & 34.3 & 21 & 30.0 \\
\hline Breast cancer stage & & & & & & \\
2 & 9 & 25.7 & 13 & 37.1 & 22 & 31.4 \\
3 & 26 & 74.3 & 22 & 62.9 & 48 & 68.6 \\
\hline Duration of & & & & & & \\
chemotherapy & & & & & & \\
$\leq 3$ years & 23 & 65.7 & 19 & 54.3 & 42 & 60.0 \\
>3 years & 12 & 34.3 & 16 & 45.7 & 28 & 40.0 \\
\hline
\end{tabular}

Table 1 showed the characteristics of age the patients are above 45 years at $70.0 \%$, the patient population is the Minangkabau ethncity $68.6 \%$, the marital status of the patient is married at $81.4 \%$, the longest since the diagnosis of cancer is less than 2 years $(70 \%)$ with the most numerous stages are stage $3(60 \%)$ and the duration of the patient undergoing chemotherapy is at most less than 3 years (60\%). The statistical test results for all patient characteristics between the intervention group and the control group were equivalent ( $\mathrm{p}$ value $\geq 0.05$ ).

Table 2: Stress Levels of Breast Cancer Patients Under Chemotherapy at Dr. M. Djamil General Hospital Padang City, West Sumatera Province, Indonesia Before and After Logotherapy Intervention Group

\begin{tabular}{lcc}
\hline \multirow{2}{*}{ Stress } & \multicolumn{2}{c}{ Groups } \\
\cline { 2 - 3 } & $\begin{array}{c}\text { Before } \\
\text { Intervention }\end{array}$ & $\begin{array}{c}\text { After } \\
\text { Intervention }\end{array}$ \\
\cline { 2 - 3 } & $\mathbf{f ( \% )}$ & $\mathbf{f ( \% )}$ \\
\hline Mild & $9(25.7)$ & $28(80.0)$ \\
Moderate & $25(71.4)$ & $6(17.1)$ \\
Heavy & $1(2.9)$ & $1(2.9)$ \\
\hline Total & $\mathbf{3 5 ( 1 0 0 )}$ & $\mathbf{3 5 ( 1 0 0 )}$ \\
\hline
\end{tabular}

Table 2 showed most of breast cancer patients in the intervention group before being given a logotherapy intervention underwent moderate stress $(71.4 \%)$. However, most breast cancer patients in the intervention group after being given the logotherapy intervention experienced mild stress $(80.0 \%)$.

Table 3: Stress Levels of Breast Cancer Patients Under Chemotherapy at Dr. M. Djamil General Hospital Padang City, West Sumatera Province, Indonesia Before and After Logotherapy Intervention of Control Group

\begin{tabular}{lcc}
\hline \multirow{2}{*}{ Stress } & \multicolumn{2}{c}{ Groups } \\
\cline { 2 - 3 } & $\begin{array}{c}\text { Before } \\
\text { Intervention }\end{array}$ & $\begin{array}{c}\text { After } \\
\text { Intervention }\end{array}$ \\
\cline { 2 - 3 } & $\mathbf{f}(\boldsymbol{\%})$ & $\mathbf{f}(\boldsymbol{\%})$ \\
\hline Mild & $8(22.9)$ & $10(28.6)$ \\
Moderate & $27(77.1)$ & $24(68.6)$ \\
Heavy & 0 & $1(2.9)$ \\
\hline Total & $\mathbf{3 5 ( 1 0 0 )}$ & $\mathbf{3 5 ( 1 0 0 )}$ \\
\hline
\end{tabular}

Table 3 showed that the control group before being given a logotherapy intervention in the intervention group underwent moderate stress $(77.1 \%)$. The control group after being given a logotherapy intervention in the intervention group underwent moderate stress $(68.6 \%)$.

Table 4: The Effect of Logotherapy on Depression in Breast Cancer Patients Under Chemotherapy

\begin{tabular}{ccccc}
\hline Stress Level & Mean & SD & SE & p value \\
\cline { 1 - 4 } Pretest & 1.7714 & 0.49024 & 0.08287 & 0.000 \\
\cline { 1 - 4 } Posttest & 1.2286 & 0.49024 & 0.08287 & \\
\hline
\end{tabular}

Table 3 showed there was an effect of logotherapy on depression in breast cancer patients under chemotherapy $(\mathrm{p}<0.05)$.

\section{DISCUSSION}

The result showed there was an effect of logotherapy on depression in breast cancer patients under chemotherapy $(\mathrm{p}<0.05)$.

Logotherapy has been investigated to reduce anxiety and depression in cancer patients. Previous study at Dharmais Cancer Hospital Jakarta, showed that anxiety and depression decreased significantly after logotherapy ( $p$ value $=0.000$ for anxiety variables and $\mathrm{p}$ value $=0.002$ for depression variables) [6]. A qualitative study found Logotherapy can also reduce depression and improve the quality of life for patients with advanced breast cancer [7].

Medical record data of Dr. M. Djamil General Hospital Padang in 2018 the number of breast cancer patients undergoing chemotherapy is 229 people. Based on the DASS 42 questionnaire distributed to 23 patients who were undergoing chemotherapy, $26 \%$ had mild stress, $70 \%$ were moderate stress and $4 \%$ had severe stress. Some studies at Dr. M. Djamil General Hospital Padang got results about the stress conditions of breast cancer patients who underwent chemotherapy.

Breast cancer patients who under chemotherapy will experience physiological and psychological side effects. Psychological side effects experienced by breast cancer 
World Journal of Research and Review (WJRR)

patients who under chemotherapy can be the emergence of feelings, such as helplessness, loss of hope, perceiving disease as a punishment, and consider themselves as a burden to others who can refer to suicidal acts [3]. Previous study showed that breast cancer patients who experience stress report more physiological symptoms, such as constipation, diarrhea, fatigue, nausea and vomiting, pain, dyspnea, insomnia, and loss of appetite [4].

This study suggests the provision of logotherapy by nursing in breast cancer patients who under chemotherapy to reduce stress experienced so that the patient's treatment process will be more optimal.

\section{CONCLUSION}

The conclusion of this study confirmed there was an effect of logotherapy on depression in breast cancer patients under chemotherapy.

\section{ACKNOWLEDGMENT}

We would like to thank all respondents who participated in this study.

\section{REFERENCES}

[1] International Agency for Research on Cancer. GLOBOCAN 2008: Cancer Incidence and Mortality Worldwide. GLOBOCAN 2008; 2008. [Accessed January 17 2019]. Available at: http://globocan.iarc.fr .

[2] Ministry of Health Republic of Indonesia. Indonesia Basic Health Survey Jakarta. 2010

[3] Teodora BA, Ianovici N, Bancila S. Modifying factors of chronic pain perception in oncological patient. Therapeutics, Pharmacology and Clinical Toxicology. 2012; 226-231.

[4] Reyes-Gibby CC, Aday LA, Anderson KO, Mendoza TR, Cleeland $\mathrm{CS}$. Pain, depression, and fatigue in communitydwelling adults with and without a history of cancer. J Pain Symptom Manage. 2006; 32: 118-28.

[5] Union for International Cancer Control. World Cancer Declaration;

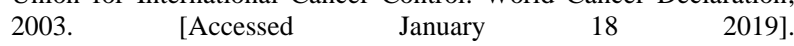
Availableat: http://www.uicc.org/world-cancer-declaration.

[6] Harahap WA, Ramadhan, Khambri D, Haryono S, Nindrea RD. Outcomes of trastuzumab therapy for 6 and 12 months in Indonesian National Health Insurance system clients with operable HER2-positive breast cancer. Asian Pac J Cancer Prev. 2018; 18: 1151-1156.

[7] Nindrea RD, Aryandono T, Lazuardi L, Dwiprahasto I. Diagnostic accuracy of different machine learning algorithms for breast cancer risk calculation: a meta-analysis. Asian Pac J Cancer Prev. 2018; 19 : 1747-1752. 